\title{
Quantitative Prediction of Voids Formation in a Growing Nickel Oxide Scale at $1373 \mathrm{~K}$
}

\author{
Kojiro Akiba*, Mitsutoshi Ueda, Kenichi Kawamura and Toshio Maruyama \\ Department of Metallurgy and Ceramics Science, Tokyo Institute of Technology, Tokyo 152-8552, Japan
}

Voids which form in oxide scales strongly influence the mechanical properties of the scale and the adherence between the metal substrate and the scale. The purpose of this study is to demonstrate a method for quantitative estimation of voids formation in NiO scale, and compare the microstructure of the scale formed on nickel at $1373 \mathrm{~K}$ with the estimation.

Calculations of ion fluxes and their divergence in $\mathrm{NiO}$ scales can predict the annihilation of the oxides which mostly occurs in the vicinity of the metal/oxide interface and the volume fraction of the voids. These predictions are in good agreement with the observed morphology of NiO scale obtained in high temperature oxidation of nickel at 1373 K. [doi:10.2320/matertrans.MER2007122]

(Received May 28, 2007; Accepted July 19, 2007; Published September 5, 2007)

Keywords: nickel oxide scale, voids formation, chemical potential distribution, divergence of ion flux

\section{Introduction}

Mechanical properties of the oxide scale and the adherence between the oxide scale and the metal substrate are influenced by the existence of voids. Exfoliation of the protective oxide scale often occurs attributed by the presence of voids.

Maruyama et al. ${ }^{1)}$ proposed that void formation in a growing oxide scale in high temperature oxidation of a metal was explained by the evaluation of the divergence of the minor ionic flux under the assumption of the major ionic flux to be responsible to establish the chemical potential distribution, and have demonstrated the validity in magnetite scale formed in high temperature oxidation of iron at $873 \mathrm{~K}$. Ueda et al. ${ }^{2)}$ improved this treatment in which all ionic fluxes were taking account into the calculation of the chemical potential gradient and quantitatively explained the position and the volume of voids formed in the magnetite scale. In magnetite, the defect of iron ion is the interstitial ion in the lower oxygen potential and is the vacancy in the higher oxygen potential. ${ }^{3)}$ The defect of oxide ion is the vacancy in the whole region. ${ }^{4)}$

$\mathrm{NiO}$ is well known as a typical metal deficient p-type semiconducing oxide with metal ion vacancy as a predominating defect ${ }^{5-9)}$ and the reported metal deficiency is as low as $\delta=$ $10^{-4}$ (in $\mathrm{Ni}_{1-\delta} \mathrm{O}$ ) at $1373 \mathrm{~K}$ in $P_{\mathrm{O}_{2}}=1 \mathrm{~atm} .{ }^{10}$ ) There have been many investigations on the high temperature oxidation of nickel and the kinetics followed the parabolic rate law, which is mainly determined by the diffusion of nickel ion. ${ }^{7,10-15)}$

The purpose of this study is to demonstrate quantitative estimation of void formation in $\mathrm{NiO}$ scale, and to compare microstructures of the oxide scales formed on nickel at $1373 \mathrm{~K}$ with the estimation.

\section{Principle}

\subsection{Mass transport in NiO scale and estimation of void formation}

Figure 1 shows a schematic illustration of chemical potential distributions of nickel and oxygen in $\mathrm{NiO}$ scale. Nickel ion diffuses toward the right hand side at which

*Graduate Student, Tokyo Institute of Technology

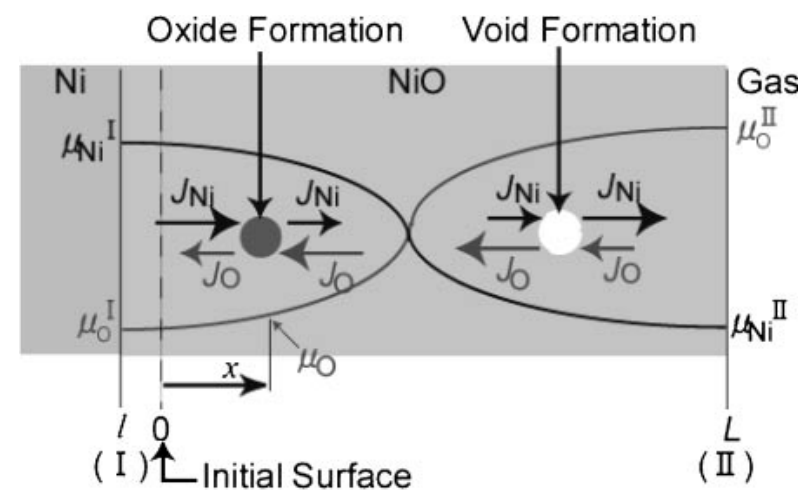

Fig. 1 Schematic illustration of chemical potential distributions of nickel and oxygen in $\mathrm{NiO}$ scale formed on nickel.

oxygen chemical potential is higher, and oxide ion diffuses to the left. Flux of an ion, $J$, at a position of $x$ in the scale is determined by the diffusivity and the electrochemical potential gradient of each ion. When the flux which flows into $x$ is larger than that flowing out, the additional oxide should form. In the opposite case, the oxide annihilates and void forms. From this point of view, the divergence of the ion flux is the quantitative measure of void formation.

\subsection{Mass flow of ions in $\mathrm{NiO}$ scale}

The non-stoichiometry of $\mathrm{NiO}$ scale is negligibly small to consider the concentration of nickel, $c_{\mathrm{Ni}}$, and oxygen, $c_{\mathrm{O}}$ in mol m $\mathrm{m}^{-3}$ to be constant.

$$
c_{\mathrm{Ni}}=c_{\mathrm{O}}=c^{*}
$$

The electro-neutrality must be maintained as follows.

$$
z_{\mathrm{Ni}} c_{\mathrm{Ni}}+z_{\mathrm{O}} c_{\mathrm{O}}=0
$$

The conservation of the ratio of number of sub-lattice sites required that the divergence of the fluxes of ions should be maintained stoichiometric ratio $(1: 1)$ in $\mathrm{NiO}$. The relation between the formation/annihilation rate of oxide in the $\mathrm{NiO}$ scale and the divergence of ion fluxes can be expressed in the following continuity equation.

$$
\partial n_{\mathrm{NiO}} / \partial t=-\partial J_{\mathrm{Ni}} / \partial x=-\partial J_{\mathrm{O}} / \partial x=n^{\prime}
$$


where $n_{\mathrm{NiO}}$ is the number of mol of the formed or annihilated oxide, and $J_{i}\left(\mathrm{~mol} \mathrm{~m}^{-2} \mathrm{~s}^{-1}\right)$ is the flux of an ion, $i$.

When $n^{\prime}$ is multiplied to the eq. (2), the divergences of total flux of ions are found to be zero.

$$
\begin{aligned}
\left(z_{\mathrm{Ni}} c_{\mathrm{Ni}}+z_{\mathrm{O}} c_{\mathrm{O}}\right) n^{\prime} & =-z_{\mathrm{Ni}} c_{\mathrm{Ni}}\left(\partial J_{\mathrm{Ni}} / \partial x\right)-z_{\mathrm{O}} c_{\mathrm{O}}\left(\partial J_{\mathrm{O}} / \partial x\right) \\
& =-c^{*} \partial\left(z_{\mathrm{Ni}} J_{\mathrm{Ni}}+z_{\mathrm{O}} J_{\mathrm{O}}\right) / \partial x=0
\end{aligned}
$$

Integration of the eq. (4) gives

$$
z_{\mathrm{Ni}} J_{\mathrm{Ni}}+z_{\mathrm{O}} J_{\mathrm{O}}=H
$$

$H$ is the constant, which is independent of the position in the scale, $x$. The equation (5) shows that the sum of ionic currents in the $\mathrm{NiO}$ scale is constant since $z_{i} F J_{i}$ is the charge flux of ion. $F$ is the Faraday constant $\left(96,500 \mathrm{C} \mathrm{mol}^{-1}\right)$.

The ion flux, $J_{i}$ is expressed as

$$
J_{i}=-c_{i} B_{i}\left(\partial \eta_{i} / \partial x\right)
$$

where $B_{i}\left(\mathrm{~mol} \mathrm{~J}^{-1} \mathrm{~m}^{2} \mathrm{~s}^{-1}\right)$ is the absolute mobility, and $\partial \eta_{i} / \partial x\left(\mathrm{~J} \mathrm{~mol}^{-1} \mathrm{~m}^{-1}\right)$ the electrochemical potential gradient.

The absolute mobility is related to the self-diffusion coefficient, $D_{i}$ as follows.

$$
D_{i}=B_{i} R T \quad \text { (Nernst-Einstein Relation) }
$$

where $R$ is the gas constant $\left(8.31 \mathrm{~J} \mathrm{~mol}^{-1} \mathrm{~K}^{-1}\right), T$ the absolute temperature $(\mathrm{K})$.

The relation between the electrochemical potential and the chemical potential, $\mu_{i}\left(\mathrm{~J} \mathrm{~mol}^{-1}\right)$ is expressed as

$$
\eta_{i}=\mu_{i}-z_{i} \eta_{\mathrm{e}}
$$

where $\eta_{\mathrm{e}}$ is the electrochemical potential of electron.

The electroneutrality must be maintained in $\mathrm{NiO}$ scale. It gives,

$$
z_{\mathrm{Ni}} J_{\mathrm{Ni}}+z_{\mathrm{O}} J_{\mathrm{O}}+z_{\mathrm{h}} J_{\mathrm{h}}+z_{\mathrm{e}} J_{\mathrm{e}}=0 \quad \text { (Electro-neutrality) }
$$

where subscripts $\mathrm{h}$ and e denote hole and electron, respectively. When the eqs. (5) and (6) are substituted in the eq. (9), following equation can be obtained.

$$
\begin{aligned}
H & +(1)\left\{-c_{\mathrm{h}} B_{\mathrm{h}}\left(\partial \eta_{\mathrm{h}} / \partial x\right)\right\}+(-1)\left\{-c_{\mathrm{e}} B_{\mathrm{e}}\left(\partial \eta_{\mathrm{e}} / \partial x\right)\right\} \\
& =H+\left(c_{\mathrm{h}} B_{\mathrm{h}}+c_{\mathrm{e}} B_{\mathrm{e}}\right)\left(\partial \eta_{\mathrm{e}} / \partial x\right)=0
\end{aligned}
$$

where the following relation (eq. (11)) is used.

$$
\left(\partial \eta_{\mathrm{h}} / \partial x\right)+\left(\partial \eta_{\mathrm{e}} / \partial x\right)=0
$$

Therefore, the electrochemical potential gradient of electron is given as

$$
\left(\partial \eta_{\mathrm{e}} / \partial x\right)=-H /\left(c_{\mathrm{h}} B_{\mathrm{h}}+c_{\mathrm{e}} B_{\mathrm{e}}\right)
$$

$H$ is given as follows with substituting the eqs. (6) and (8) into the eq. (5),

$$
\begin{aligned}
H= & z_{\mathrm{Ni}} J_{\mathrm{Ni}}+z_{\mathrm{O}} J_{\mathrm{O}} \\
= & -\left\{z_{\mathrm{Ni}} c_{\mathrm{Ni}} B_{\mathrm{Ni}}\left(\partial \eta_{\mathrm{Ni}} / \partial x\right)+z_{\mathrm{O}} c_{\mathrm{O}} B_{\mathrm{O}}\left(\partial \eta_{\mathrm{O}} / \partial x\right)\right\} \\
= & -\left\{z_{\mathrm{Ni}} c_{\mathrm{Ni}} B_{\mathrm{Ni}}\left(\partial \mu_{\mathrm{Ni}} / \partial x\right)+z_{\mathrm{O}} c_{\mathrm{O}} B_{\mathrm{O}}\left(\partial \mu_{\mathrm{O}} / \partial x\right)\right\} \\
& +\left(z_{\mathrm{Ni}}^{2} c_{\mathrm{Ni}} B_{\mathrm{Ni}}+z_{\mathrm{O}}^{2} c_{\mathrm{O}} B_{\mathrm{O}}\right)\left(\partial \eta_{\mathrm{e}} / \partial x\right)
\end{aligned}
$$

$\alpha$ and $\beta$ are defined as eqs. (14) and (15) for simplicity, and they correspond to the contribution of ionic and electronic transports. $H$ can be given as eq. (16) with the chemical potential gradient of ions.

$$
\begin{gathered}
\alpha=z_{\mathrm{Ni}}^{2} c_{\mathrm{Ni}} B_{\mathrm{Ni}}+z_{\mathrm{O}}^{2} c_{\mathrm{O}} B_{\mathrm{O}} \\
\beta=c_{\mathrm{h}} B_{\mathrm{h}}+c_{\mathrm{e}} B_{\mathrm{e}} \\
H=-\{\beta /(\alpha+\beta)\}\left\{z_{\mathrm{Ni}} c_{\mathrm{Ni}} B_{\mathrm{Ni}}\left(\partial \mu_{\mathrm{Ni}} / \partial x\right)\right. \\
\left.+z_{\mathrm{O}} c_{\mathrm{O}} B_{\mathrm{O}}\left(\partial \mu_{\mathrm{O}} / \partial x\right)\right\}=-t_{\mathrm{e}}\left\{z_{\mathrm{Ni}} c_{\mathrm{Ni}} B_{\mathrm{Ni}}\left(\partial \mu_{\mathrm{Ni}} / \partial x\right)\right. \\
\left.+z_{\mathrm{O}} c_{\mathrm{O}} B_{\mathrm{O}}\left(\partial \mu_{\mathrm{O}} / \partial x\right)\right\}
\end{gathered}
$$

where $t_{\mathrm{e}}$ is electronic transference number.

The Gibbs-Duhem relation in $\mathrm{NiO}$ is given as

$$
c_{\mathrm{Ni}}\left(\partial \mu_{\mathrm{Ni}} / \partial x\right)+c_{\mathrm{O}}\left(\partial \mu_{\mathrm{O}} / \partial x\right)=0
$$

Substitution of the eq. (17) into eq. (16) gives the following equation.

$$
H=-\left(1 / z_{\mathrm{O}}\right)\{\alpha \beta /(\alpha+\beta)\}\left(\partial \mu_{\mathrm{O}} / \partial x\right)
$$

\subsection{Chemical potential distribution in $\mathrm{NiO}$ scale}

The integration of the eq. (18) from $x=l$ (the metal/oxide interface, $\mu_{\mathrm{O}}=\mu_{\mathrm{O}}^{\mathrm{I}}$ ) to $x=L$ (the oxide/gas interface, $\left.\mu_{\mathrm{O}}=\mu_{\mathrm{O}}^{\mathrm{II}}\right)$ gives

$$
\begin{aligned}
\int_{\mu_{\mathrm{O}}^{\mathrm{I}}}^{\mu_{\mathrm{O}}^{\mathrm{II}}}\{\alpha \beta /(\alpha+\beta)\} \partial \mu_{\mathrm{O}} & =-z_{\mathrm{O}} \int_{l}^{L} H \partial x \\
& =-z_{\mathrm{O}} H(L-l)=k(=\text { const. })
\end{aligned}
$$

On the other hand, integration of the eq. (18) from $x=l$ $\left(\mu_{\mathrm{O}}=\mu_{\mathrm{O}}^{\mathrm{I}}\right)$ to $x=x$ (a certain position in the scale, $\left.\mu_{\mathrm{O}}=\mu_{\mathrm{O}}\right)$ gives

$$
\begin{aligned}
& \int_{\mu_{\mathrm{O}}^{\mathrm{I}}}^{\mu_{\mathrm{O}}}\{\alpha \beta /(\alpha+\beta)\} \partial \mu_{\mathrm{O}} \\
& \quad=-z_{\mathrm{O}} \int_{l}^{x} H \partial x=-z_{\mathrm{O}} H(x-l)
\end{aligned}
$$

The ratio of the eqs. (19) and (20) is represented as follows.

$$
\begin{aligned}
(x-l) /(L-l)= & {\left[\int_{\mu_{\mathrm{O}}^{\mathrm{I}}}^{\mu_{\mathrm{O}}}\{\alpha \beta /(\alpha+\beta)\} \partial \mu_{\mathrm{O}}\right] } \\
& /\left[\int_{\mu_{\mathrm{O}}^{\mathrm{I}}}^{\mu_{\mathrm{O}}^{\mathrm{II}}}\{\alpha \beta /(\alpha+\beta)\} \partial \mu_{\mathrm{O}}\right] \\
= & \int_{\mu_{\mathrm{O}}^{\mathrm{I}}}^{\mu_{\mathrm{O}}^{\mathrm{I}}}\{\alpha \beta /(\alpha+\beta)\} \partial \mu_{\mathrm{O}} / k
\end{aligned}
$$

From the eq. (21), one can obtain the chemical potential distribution of oxygen in the oxide scale.

The chemical potential gradient of oxygen can be given as differentiation of eq. (21).

$d \mu_{\mathrm{O}} / d x=k(\alpha+\beta) /\{(L-l) \alpha \beta\}=-z_{\mathrm{O}} H(\alpha+\beta) /(\alpha \beta)$

Thus, the electrochemical potential gradient of oxygen is obtained as

$$
\begin{aligned}
\partial \eta_{\mathrm{O}} / \partial x & =\partial \mu_{\mathrm{O}} / \partial x-z_{\mathrm{O}}\left(\partial \eta_{\mathrm{e}} / \partial x\right) \\
& =[k(\alpha+\beta) /\{(L-l) \alpha \beta\}]-[k /\{(L-l) \beta\}] \\
& =k /\{(L-l) \alpha\}=\{\beta /(\alpha+\beta)\}\left(\partial \mu_{\mathrm{O}} / \partial x\right) \\
& =t_{\mathrm{e}}\left(\partial \mu_{\mathrm{O}} / \partial x\right)
\end{aligned}
$$

Since $\mathrm{NiO}$ is a hole conductor $\left(\beta \gg \alpha, t_{\mathrm{e}}=1\right)$, the equation (21) can be written as 


$$
\begin{aligned}
(x-l) /(L-l) & =\left(\int_{\mu_{\mathrm{O}}^{\mathrm{I}}}^{\mu_{\mathrm{O}}} \alpha \partial \mu_{\mathrm{O}}\right) /\left(\int_{\mu_{\mathrm{O}}^{\mathrm{I}}}^{\mu_{\mathrm{O}}^{\mathrm{I}}} \alpha \partial \mu_{\mathrm{O}}\right) \\
& =\int_{\mu_{\mathrm{O}}^{\mathrm{I}}}^{\mu_{\mathrm{O}}} \alpha \partial \mu_{\mathrm{O}} / k
\end{aligned}
$$

The equation (22) can be simplified as

$$
d \mu_{\mathrm{O}} / d x=k /\{(L-l) \alpha\}=-z_{\mathrm{O}} H / \alpha
$$

and the electrochemical potential gradient can be

$$
\partial \eta_{\mathrm{O}} / \partial x=\partial \mu_{\mathrm{O}} / \partial x
$$

\subsection{Parabolic rate constant}

Growth rate of the outer scale is the velocity of displacement of the oxide/gas interface, $d L / d t$ which is proportional to the flux of nickel ion at the oxide/gas interface, $J_{\mathrm{Ni}}^{\mathrm{II}}$.

$$
\begin{aligned}
d L / d t & =V_{\mathrm{NiO}} J_{\mathrm{Ni}}^{\mathrm{II}} / c_{\mathrm{Ni}}=-B_{\mathrm{Ni}}^{\mathrm{II}}\left(\partial \eta_{\mathrm{Ni}} / \partial x\right)^{\mathrm{II}} \\
& =\left(c_{\mathrm{O}} B_{\mathrm{Ni}}^{\mathrm{II}} / c_{\mathrm{Ni}}\right)\left(\partial \eta_{\mathrm{O}} / \partial x\right)^{\mathrm{II}}
\end{aligned}
$$

where $V_{\mathrm{NiO}}$ is the molar volume of $\mathrm{NiO}$ which is $1 \mathrm{~m}^{3} \mathrm{~mol}^{-1}$ by the definition of $c_{i}$. In deriving the above equation, the Gibbs-Duhem relation was adopted. Using the eqs. (25) and (26), the eq. (27) can be written as,

$$
\begin{aligned}
d L / d t & =\left(c_{\mathrm{O}} B_{\mathrm{Ni}}^{\mathrm{II}} k / c_{\mathrm{Ni}}\right) /\left\{(L-l) \alpha^{\mathrm{II}}\right\} \\
& =-\left(z_{\mathrm{Ni}} B_{\mathrm{Ni}}^{\mathrm{II}} k / z_{\mathrm{O}}\right) /\left\{(L-l) \alpha^{\mathrm{II}}\right\} \\
& =z_{\mathrm{Ni}}^{2} c_{\mathrm{Ni}} B_{\mathrm{Ni}}^{\mathrm{II}} k /\left\{z_{\mathrm{O}}^{2} c_{\mathrm{O}}(L-l) \alpha^{\mathrm{II}}\right\}
\end{aligned}
$$

On the other hand, the growth rate of the inner scale is equal to the velocity of displacement of the oxide/gas interface, $d l / d t$, which is proportional to the flux of oxide ion at the oxide/metal interface,

$$
\begin{aligned}
d l / d t & =V_{\mathrm{NiO}} J_{\mathrm{O}}^{\mathrm{I}} / c_{\mathrm{O}}=-B_{\mathrm{O}}^{\mathrm{I}}\left(\partial \eta_{\mathrm{O}} / \partial x\right)^{\mathrm{I}}=-k B_{\mathrm{O}}^{\mathrm{I}} /\left\{(L-l) \alpha^{\mathrm{I}}\right\} \\
& =-z_{\mathrm{O}}^{2} c_{\mathrm{O}} B_{\mathrm{O}}^{\mathrm{I}} k /\left\{z_{\mathrm{O}}^{2} c_{\mathrm{O}}(L-l) \alpha^{\mathrm{I}}\right\}
\end{aligned}
$$

The growth rate of the total scale is represented as

$$
\begin{aligned}
d(L-l) / d t= & d L / d t-d l / d t \\
= & \left\{k /\left(z_{\mathrm{O}}^{2} c_{\mathrm{O}}\right)\right\}\left\{\left(z_{\mathrm{Ni}}^{2} c_{\mathrm{Ni}} B_{\mathrm{Ni}}^{\mathrm{II}} / \alpha^{\mathrm{II}}\right)\right. \\
& \left.+\left(z_{\mathrm{O}}^{2} c_{\mathrm{O}} B_{\mathrm{O}}^{\mathrm{I}} / \alpha^{\mathrm{I}}\right)\right\}\{1 /(L-l)\}
\end{aligned}
$$

Parabolic rate constant, $k_{\mathrm{p}}$ gives

$$
(L-l)^{2}=2 k_{\mathrm{P}} t
$$

Therefore, $k_{\mathrm{p}}$ is described as

$$
k_{\mathrm{P}}=\left\{k /\left(z_{\mathrm{O}}^{2} c_{\mathrm{O}}\right)\right\}\left(z_{\mathrm{Ni}}^{2} c_{\mathrm{Ni}} B_{\mathrm{Ni}}^{\mathrm{II}} / \alpha^{\mathrm{II}}+z_{\mathrm{O}}^{2} c_{\mathrm{O}} B_{\mathrm{O}}^{\mathrm{I}} / \alpha^{\mathrm{I}}\right)
$$

\subsection{Thickness ratio of inner and outer scales}

The equations (28) and (29) give the thickness ratio of inner and outer scales, $r$ to be

$$
\begin{aligned}
r & =-l / L=\int_{0}^{t}\{d(-l) / d t\} d t / \int_{0}^{t}(d L / d t) d t \\
& =\left(z_{\mathrm{O}}^{2} c_{\mathrm{O}} B_{\mathrm{O}}^{\mathrm{I}} \alpha^{\mathrm{II}}\right) /\left(z_{\mathrm{Ni}}^{2} c_{\mathrm{Ni}} B_{\mathrm{Ni}}^{\mathrm{II}} \alpha^{\mathrm{I}}\right)
\end{aligned}
$$

\subsection{Volume fraction of voids in $\mathrm{NiO}$ scale}

The volume of voids formed in the $\mathrm{NiO}$ scale in per unit time on per unit area of the nickel substrate, $d V_{\text {void }}^{\text {calc }} / d t$ is proportional to the difference of the flux of oxygen injected at the oxide/gas interface, $J_{\mathrm{O}}^{\mathrm{II}}$, and the one ejected at the metal/ oxide interface, $J_{\mathrm{O}}^{\mathrm{I}}$.

$$
\begin{aligned}
d V_{\text {void }}^{\text {calc }} / d t & =\left(V_{\mathrm{NiO}} / c_{\mathrm{O}}\right)\left(J_{\mathrm{O}}^{\mathrm{II}}-J_{\mathrm{O}}^{\mathrm{I}}\right) \\
& =k\left(\alpha^{\mathrm{II}} B_{\mathrm{O}}^{\mathrm{I}}-\alpha^{\mathrm{I}} B_{\mathrm{O}}^{\mathrm{II}}\right) /\left\{\alpha^{\mathrm{I}} \alpha^{\mathrm{II}}(L-l)\right\}
\end{aligned}
$$

The scale thickness of $(L-l)$ in the eq. (34) can be written using the eqs. (31) and (32) as

$$
\begin{aligned}
(L-l) & =\sqrt{2 k_{\mathrm{P}} t}=\left[\left\{2 k /\left(z_{\mathrm{O}}^{2} c_{\mathrm{O}}\right)\right\}\left\{\left(z_{\mathrm{Ni}}^{2} c_{\mathrm{Ni}} B_{\mathrm{Ni}}^{\mathrm{II}} / \alpha^{\mathrm{II}}\right)+\left(z_{\mathrm{O}}^{2} c_{\mathrm{O}} B_{\mathrm{O}}^{\mathrm{I}} / \alpha^{\mathrm{I}}\right)\right\}\right]^{1 / 2} t^{1 / 2} \\
& =\left\{2 k\left(z_{\mathrm{Ni}}^{2} c_{\mathrm{Ni}} B_{\mathrm{Ni}}^{\mathrm{II}} \alpha^{\mathrm{I}}+z_{\mathrm{O}}^{2} c_{\mathrm{O}} B_{\mathrm{O}}^{\mathrm{I}} \alpha^{\mathrm{II}}\right) /\left(z_{\mathrm{O}}^{2} c_{\mathrm{O}} \alpha^{\mathrm{I}} \alpha^{\mathrm{II}}\right)\right\}^{1 / 2} t^{1 / 2}
\end{aligned}
$$

Then, the eq. (34) is written as

$$
d V_{\text {void }}^{\text {calc }} / d t=\left[z_{\mathrm{O}}^{2} c_{\mathrm{O}} k\left(\alpha^{\mathrm{II}} B_{\mathrm{O}}^{\mathrm{I}}-\alpha^{\mathrm{I}} B_{\mathrm{O}}^{\mathrm{II}}\right)^{2} /\left\{2 \alpha^{\mathrm{I}} \alpha^{\mathrm{II}}\left(z_{\mathrm{Ni}}^{2} c_{\mathrm{Ni}} B_{\mathrm{Ni}}^{\mathrm{II}} \alpha^{\mathrm{I}}+z_{\mathrm{O}}^{2} c_{\mathrm{O}} B_{\mathrm{O}}^{\mathrm{I}} \alpha^{\mathrm{II}}\right)\right\}\right]^{1 / 2} t^{-1 / 2}
$$

The integration of the eq. (36) from $t=0$ to $t=t$ gives the volume of voids formed in the NiO scale on per unit area of the nickel substrate as

$$
\begin{aligned}
\int_{0}^{V_{\text {void }}^{\text {calc }} d V_{\text {void }}^{\text {calc }}}=\left[z_{\mathrm{O}}^{2} c_{\mathrm{O}} k\left(\alpha^{\mathrm{II}} B_{\mathrm{O}}^{\mathrm{I}}-\alpha^{\mathrm{I}} B_{\mathrm{O}}^{\mathrm{II}}\right)^{2} /\left\{2 \alpha^{\mathrm{I}} \alpha^{\mathrm{II}}\left(z_{\mathrm{Ni}}^{2} c_{\mathrm{Ni}} B_{\mathrm{Ni}}^{\mathrm{II}} \alpha^{\mathrm{I}}+z_{\mathrm{O}}^{2} c_{\mathrm{O}} B_{\mathrm{O}}^{\mathrm{I}} \alpha^{\mathrm{II}}\right)\right\}\right]^{1 / 2} \int_{0}^{t} t^{-1 / 2} d t \\
V_{\text {void }}^{\text {calc }}=\left[2 z_{\mathrm{O}}^{2} c_{\mathrm{O}} k\left(\alpha^{\mathrm{II}} B_{\mathrm{O}}^{\mathrm{I}}-\alpha^{\mathrm{I}} B_{\mathrm{O}}^{\mathrm{II}}\right)^{2} /\left\{\alpha^{\mathrm{I}} \alpha^{\mathrm{II}}\left(z_{\mathrm{Ni}}^{2} c_{\mathrm{Ni}} B_{\mathrm{Ni}}^{\mathrm{II}} \alpha^{\mathrm{I}}+z_{\mathrm{O}}^{2} c_{\mathrm{O}} B_{\mathrm{O}}^{\mathrm{I}} \alpha^{\mathrm{II}}\right)\right\}\right]^{1 / 2} t^{1 / 2}
\end{aligned}
$$

The fraction of volume of voids to that of the scale, $f_{\text {void }}^{\text {calc }}$, is expressed as

$$
f_{\text {void }}^{\text {calc }}=V_{\text {void }}^{\text {calc }} /\{1 \times 1 \times(L-l)\}=z_{\mathrm{O}}^{2} c_{\mathrm{O}}\left(\alpha^{\mathrm{II}} B_{\mathrm{O}}^{\mathrm{I}}-\alpha^{\mathrm{I}} B_{\mathrm{O}}^{\mathrm{II}}\right) /\left(z_{\mathrm{Ni}}^{2} c_{\mathrm{Ni}} B_{\mathrm{Ni}}^{\mathrm{II}} \alpha^{\mathrm{I}}+z_{\mathrm{O}}^{2} c_{\mathrm{O}} B_{\mathrm{O}}^{\mathrm{I}} \alpha^{\mathrm{II}}\right)
$$

The equation (39) indicates that $f_{\text {void }}^{\text {calc }}$ is independent of time but depends on $P_{\mathrm{O}_{2}}$.

\section{Experimental}

\subsection{Sample preparation}

Nickel sheets $(99.95 \%$, Nilaco Corporation) was cut into the coupon $10 \times 10 \times 1\left(\mathrm{~mm}^{3}\right)$ in size. After annealed in vacuum at $1573 \mathrm{~K}$ for $36 \mathrm{ks}$, the samples were polished to a mirror finish with abrasive papers (\#600-\#2000) and diamond paste of $4 \mu \mathrm{m}$. 
(a)

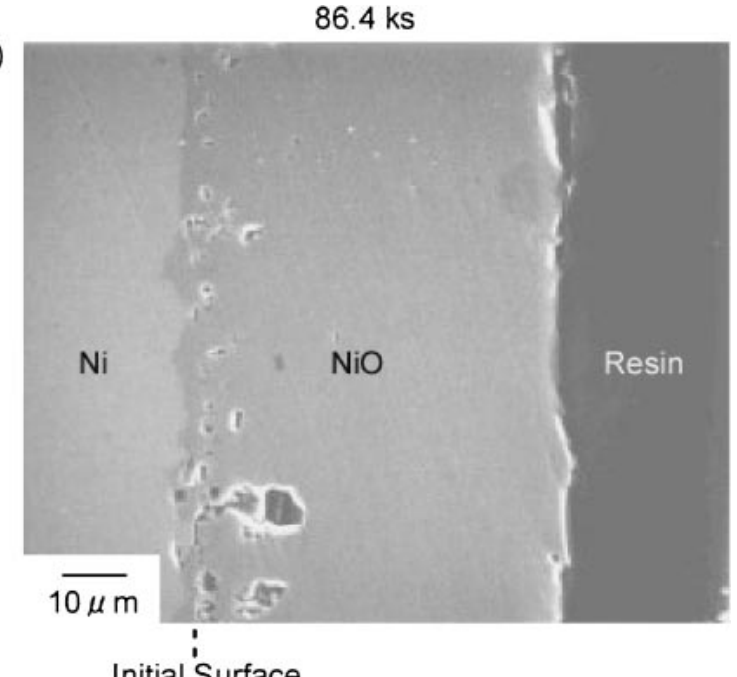

$172.8 \mathrm{ks}$

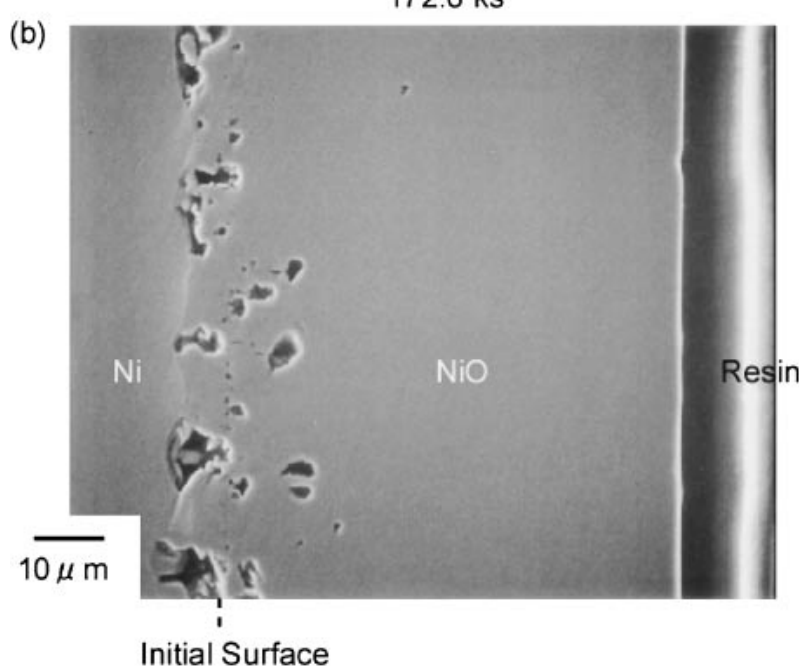

Fig. 2 SEM images of the cross-section of $\mathrm{NiO}$ scale oxidized in the high $P_{\mathrm{O}_{2}}$ atmosphere $\left(P_{\mathrm{O}_{2}}=2.1 \times 10^{4} \mathrm{~Pa}\right)$ for (a) $86.4 \mathrm{ks}$, (b) $172.8 \mathrm{ks}$.

\subsection{Oxidation experiments}

Samples were oxidized at $1373 \mathrm{~K}$ in $\mathrm{Ar}-21 \% \mathrm{O}_{2}$ gas mixture $\left(P_{\mathrm{O}_{2}}=2.1 \times 10^{4} \mathrm{~Pa}\right.$, the high $P_{\mathrm{O}_{2}}$ atmosphere $)$ and in $\mathrm{CO}-\mathrm{CO}_{2}$ gas mixture $\left(P_{\mathrm{O}_{2}}=2.0 \times 10^{-2} \mathrm{~Pa}\right.$, the low $P_{\mathrm{O}_{2}}$ atmosphere) for up to $172.8 \mathrm{ks}$.

Marker experiment was carried out to determine the initial surface. Before the oxidation, platinum paste was applied on nickel sheets prepared in the same procedure mentioned above. Then, the sample was oxidized at $1373 \mathrm{~K}$ in the high $P_{\mathrm{O}_{2}}$ atmosphere for $86.4 \mathrm{ks}$.

During the oxidation, the atmosphere was monitored by an oxygen sensor of $\mathrm{CaO}$-stabilized $\mathrm{ZrO}_{2} \quad(\mathrm{CSZ})$ and the temperature was measured by a thermocouple(R). They were set just beneath the sample. After cooling the sample, the scale morphology was observed with SEM. The scale and voids were traced on a section paper which was put on the enlarged cross-sectional SEM image, and the area fraction of voids in the scale was measured. The volume fraction of voids in the scale can be regarded equal to the cross-sectional area fraction of voids in the scale. ${ }^{16)}$ (a)

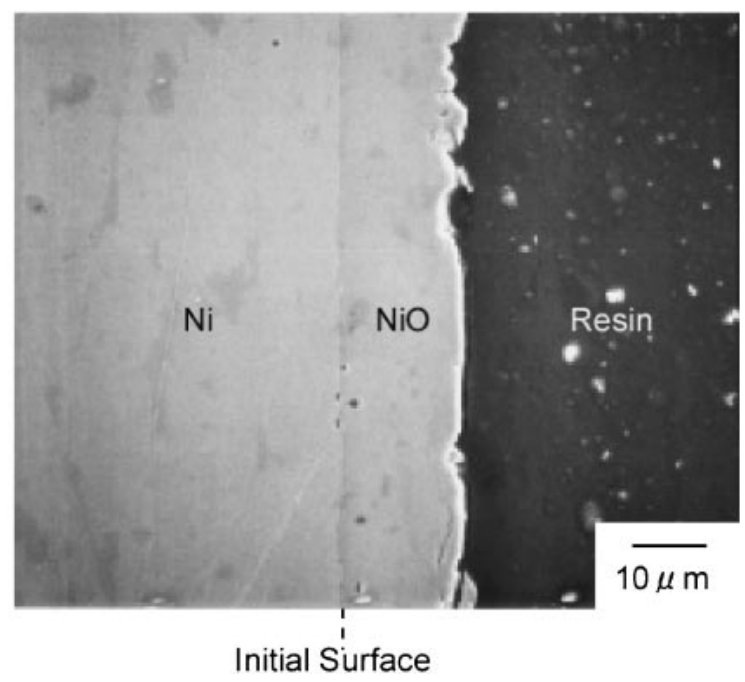

$172.8 \mathrm{ks}$

(b)

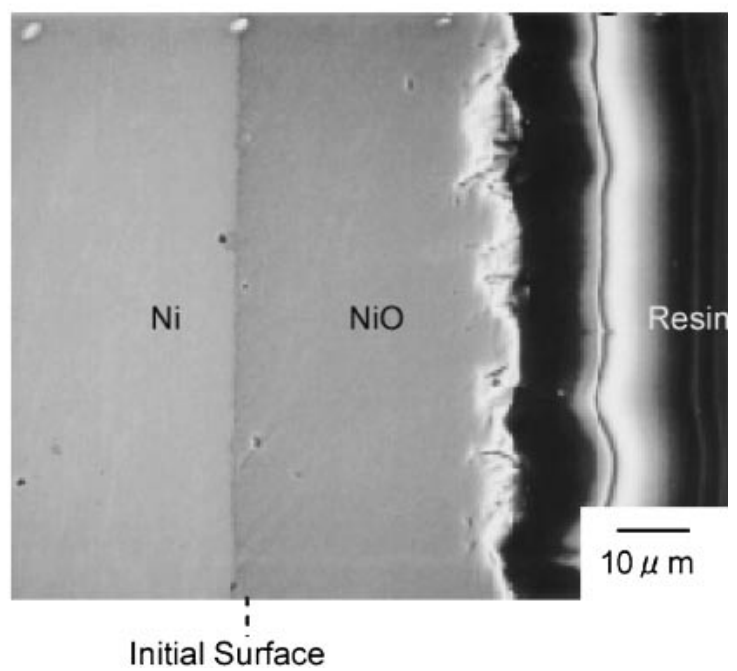

Fig. 3 SEM images of the cross-section of $\mathrm{NiO}$ scale oxidized in the low $P_{\mathrm{O}_{2}}$ atmosphere $\left(P_{\mathrm{O}_{2}}=2.0 \times 10^{-2} \mathrm{~Pa}\right)$ for (a) $86.4 \mathrm{ks}$, (b) $172.8 \mathrm{ks}$.

\section{Results}

\subsection{Cross-section of $\mathrm{NiO}$ scale and voids in the scale}

Figure 2 shows the cross-sections of $\mathrm{NiO}$ scales formed under the high $P_{\mathrm{O}_{2}}$ atmosphere of $P_{\mathrm{O}_{2}}=2.1 \times 10^{4} \mathrm{~Pa}$. Voids are preferentially observed in the vicinity of the metal/oxide interface. Figure 3 shows the cross-section of $\mathrm{NiO}$ scales formed under the low $P_{\mathrm{O}_{2}}$ atmosphere of $P_{\mathrm{O}_{2}}=2.0 \times 10^{-2}$ $\mathrm{Pa}$. Voids are also observed in the vicinity of the metal/oxide interface. However, the amount of voids is less and the size is smaller than those in the scale formed under the high $P_{\mathrm{O}_{2}}$ atmosphere.

The volume fraction of voids in the scale is shown in Fig. 4. The volume fraction is independent of oxidation time but depends on the oxygen partial pressure in the atmosphere.

\subsection{Growth rate of $\mathrm{NiO}$ scale}

Figure 5 shows the parabolic plots of total scale thickness. The scale growth in both atmospheres follows the parabolic 

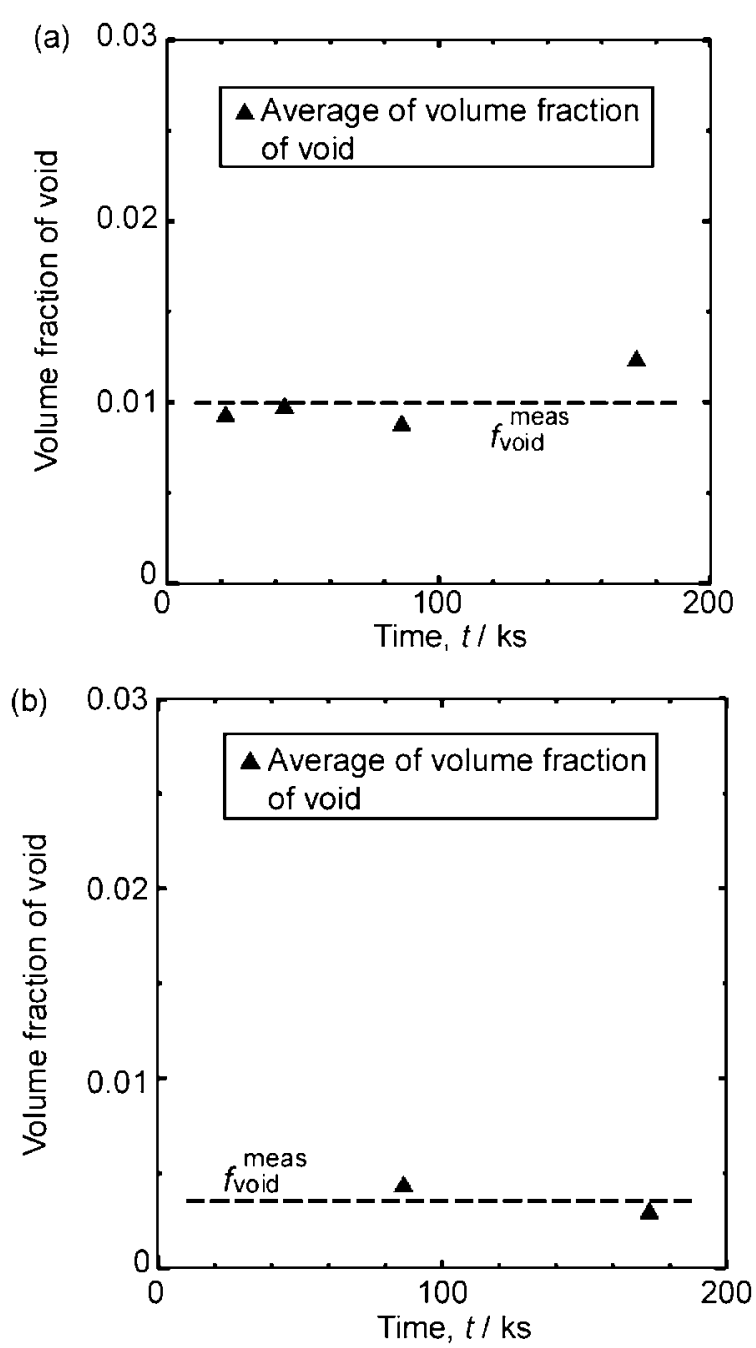

Fig. 4 The area fraction of voids in the scale measured in the cross sections of the sample oxidized in (a) the high $P_{\mathrm{O}_{2}}$ atmosphere $\left(P_{\mathrm{O}_{2}}=2.1 \times\right.$ $\left.10^{4} \mathrm{~Pa}\right),(\mathrm{b})$ the low $P_{\mathrm{O}_{2}}$ atmosphere $\left(P_{\mathrm{O}_{2}}=2.0 \times 10^{-2} \mathrm{~Pa}\right)$.

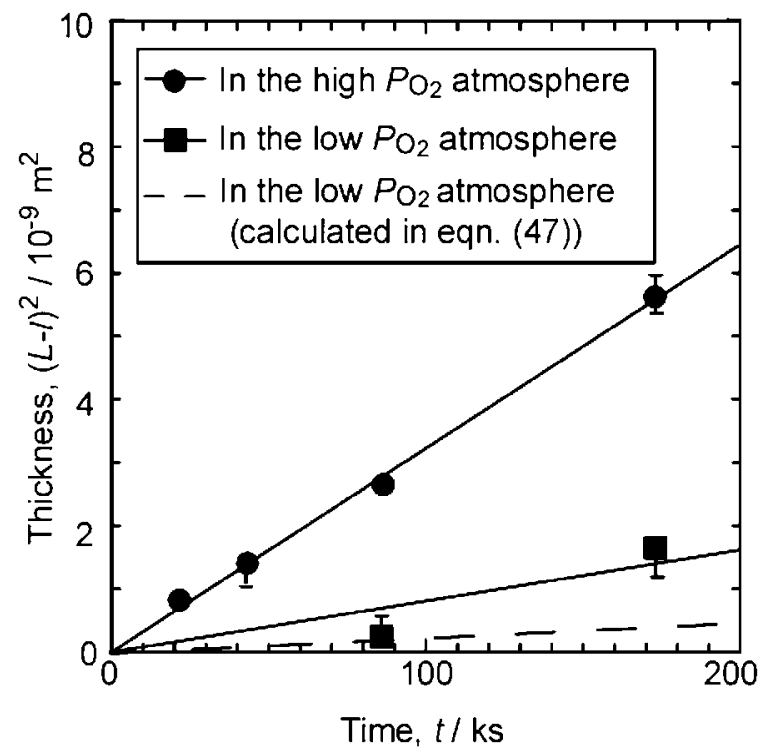

Fig. 5 Parabolic plots for the total scale thickness obtained from the experiment and calculated in the eq. (47) for the low $P_{\mathrm{O}_{2}}$ atmosphere.

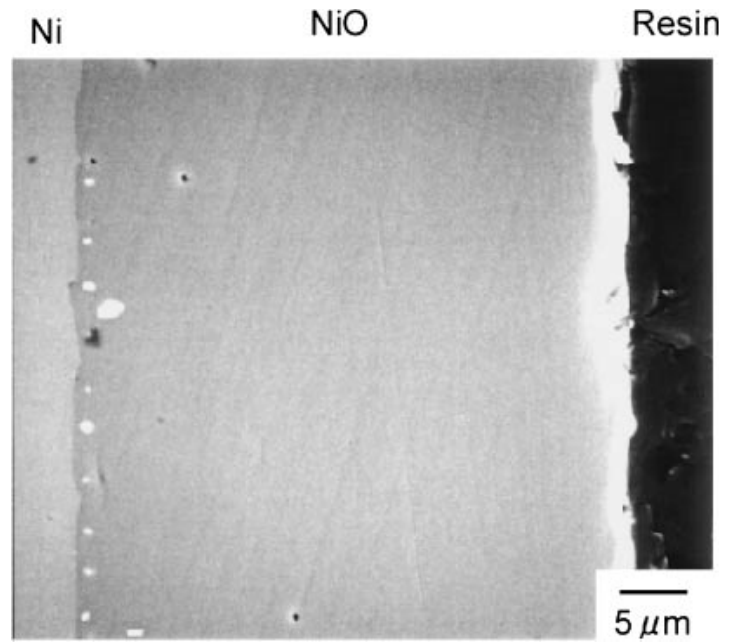

Fig. 6 Cross section of $\mathrm{NiO}$ scale formed in the oxidation for $86.4 \mathrm{ks}$ in the high $P_{\mathrm{O}_{2}}$ atmosphere $\left(P_{\mathrm{O}_{2}}=2.1 \times 10^{4} \mathrm{~Pa}\right)$ with $\mathrm{Pt}$ marker.

rate law. Then, parabolic rate constants are obtained as follows.

$$
\begin{aligned}
k_{\mathrm{p}}^{\text {high }}= & 1.6 \times 10^{-14} \mathrm{~m}^{2} \mathrm{~s}^{-1} \\
& \left(\text { in the high } P_{\mathrm{O}_{2}} \text { atmosphere }\right) \\
k_{\mathrm{p}}^{\text {low }}= & 4.1 \times 10^{-15} \mathrm{~m}^{2} \mathrm{~s}^{-1}
\end{aligned}
$$$$
\text { (in the low } P_{\mathrm{O}_{2}} \text { atmosphere) }
$$

\subsection{Thickness ratio of inner and outer scales}

Figure 6 shows the cross section of $\mathrm{NiO}$ scale with platinum marker after oxidation at the high $P_{\mathrm{O}_{2}}$ atmosphere for $86.4 \mathrm{ks}$. The markers are located parallel to the metal/ oxide interface. Their position represents the initial surface before oxidation. The thickness ratio was obtained as

$$
r=-l / L=0.016
$$

\section{Discussion}

\subsection{Effective diffusion coefficients of nickel and oxide ions in $\mathrm{NiO}$ scale}

There have been many investigations on high temperature oxidation of nickel in which polycrystalline scale is formed. The reported parabolic rate constants frequently exhibited the oxygen pressure dependence of $P_{\mathrm{O}_{2}}^{1 / 6}$ so that the predominant defect of nickel is a doubly ionized vacancy. The schottky equilibrium indicates that defect of oxide ion is a doubly ionized oxygen vacancy and the oxygen pressure dependence of the vacancy concentration is of $P_{\mathrm{O}_{2}}^{-1 / 6}$.

The mass transport process in polycrystalline scale is contributed by both bulk and grain boundary diffusions. The diffusion coefficients evaluated from the oxidation kinetics is the effective diffusion coefficients. Stubican et al. ${ }^{17)}$ measured grain boundary diffusion of divalent cobalt ion in the polycrystalline film of $\mathrm{NiO}$ and $\mathrm{NiO}$ bicrystal at $1023 \mathrm{~K}$, and reported that the oxygen pressure dependence of the grain boundary diffusion coefficients was similar to the one of the bulk diffusion coefficients. From this results, the oxygen partial pressure dependence of the grain boundary diffusion 


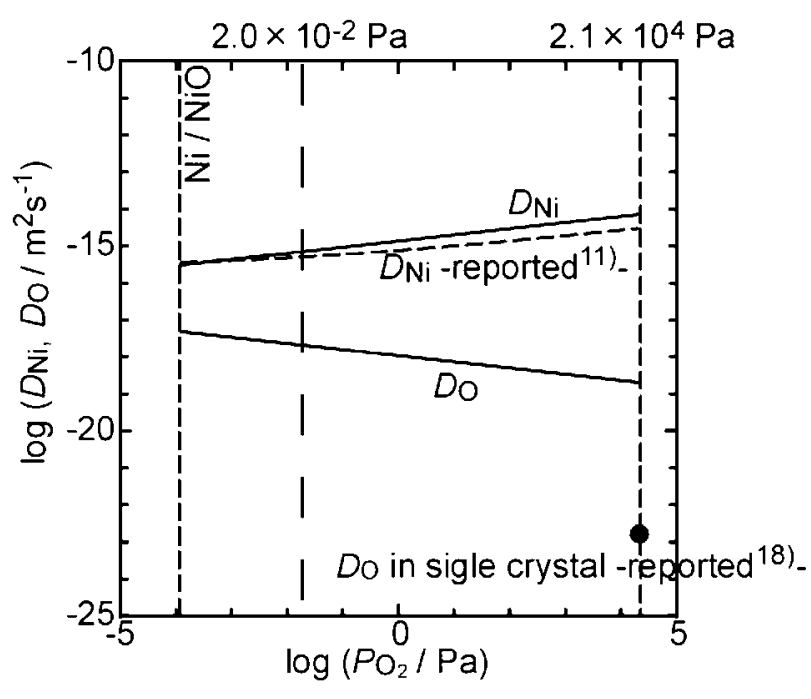

Fig. 7 Effective diffusion coefficients of nickel and oxygen in $\mathrm{NiO}$ scale.

of nickel and oxygen in the $\mathrm{NiO}$ scale is considered to be the same to that of the bulk diffusion. Therefore, the $P_{\mathrm{O}_{2}}$ dependence of effective diffusion coefficients in $\mathrm{NiO}$ scales can be described as

$$
\begin{aligned}
& D_{\mathrm{Ni}}=\boldsymbol{A} P_{\mathrm{O}_{2}}^{1 / 6} \\
& D_{\mathrm{O}}=\boldsymbol{B} P_{\mathrm{O}_{2}}^{-1 / 6}
\end{aligned}
$$

where $\boldsymbol{A}$ and $\boldsymbol{B}$ are constants to be obtained experimentally. These two constants are derived from the simultaneous equations of the eqs. (32) and (33) by substituting the obtained kinetic parameters, $k_{\mathrm{p}}$ and $r$ shown in the eqs. (40), (41) and (42). In this study, $k_{\mathrm{p}}$ and $r$ in the high $P_{\mathrm{O}_{2}}$ atmosphere are used to calculate $\boldsymbol{A}$ and $\boldsymbol{B}$, because both of them are obtained in the identical condition. The constants, $\boldsymbol{A}$ and $\boldsymbol{B}$ in the eqs. (43) and (44) are respectively obtained as,

$$
\begin{aligned}
& \boldsymbol{A}=1.0 \times 10^{-15} \mathrm{~m}^{2} \mathrm{~s}^{-1} \mathrm{~Pa}^{-1 / 6} \\
& \boldsymbol{B}=8.3 \times 10^{-19} \mathrm{~m}^{2} \mathrm{~s}^{-1} \mathrm{~Pa}^{1 / 6}
\end{aligned}
$$

Figure 7 shows the effective diffusion coefficients obtained in this study as a function of oxygen chemical potential with previously reported values. The effective diffusion coefficient of nickel reported by Maruyama et al. ${ }^{11)}$ with high temperature oxidation experiments of nickel is almost the same to that obtained in this study. On the other hand, the effective diffusion coefficient of oxygen reported by Dubois et al. ${ }^{18)}$ with tracer experiments in single crystal $\mathrm{NiO}$ is 4 orders smaller than that obtained in this study. It indicates that the contribution of grain boundary diffusion is large in the case of polycrystalline $\mathrm{NiO}$ scale.

Substituting the diffusivities of the eqs. (45) and (46) into the eq. (32), $k_{\mathrm{p}}$ in the low $P_{\mathrm{O}_{2}}$ atmosphere was calculated as

$$
k_{\mathrm{p}}^{\text {low,calc }}=9.6 \times 10^{-16} \mathrm{~m}^{2} \mathrm{~s}^{-1}
$$

The parabolic plot of this value is shown by the dotted line in Fig. 5. The calculation reasonably predicted the experimentally obtained $k_{\mathrm{p}}$ in the low $P_{\mathrm{O}_{2}}$ atmosphere.

\subsection{Chemical potential distribution of oxygen in the $\mathrm{NiO}$ scale}

Using the effective diffusion coefficients of ions, the

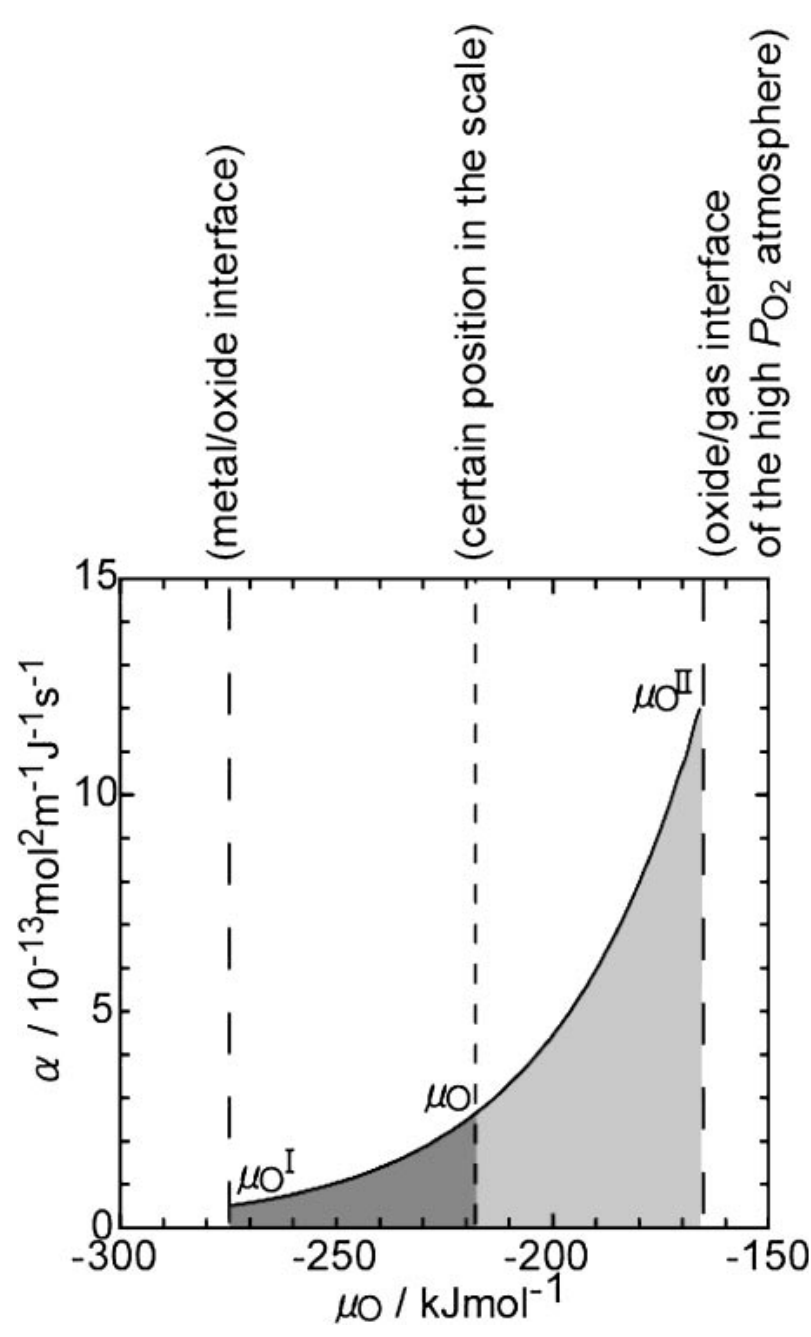

Fig. $8 \alpha$ versus chemical potential of oxygen.

chemical potential distribution of oxygen in the $\mathrm{NiO}$ scale formed at $1373 \mathrm{~K}$ can be calculated. The equation (24) gives the relation between the position and the chemical potential of oxygen in the scale. Figure 8 shows $\alpha$ against the oxygen chemical potential for the experiment in the high $P_{\mathrm{O}_{2}}$ atmosphere as an example. The denominator of the eq. (24) is equal to the area under the curve of $\alpha$ between the chemical potential of oxygen, $\mu_{\mathrm{O}}^{\mathrm{I}}$ (the metal/oxide interface) and $\mu_{\mathrm{O}}^{\mathrm{II}}$ (the oxide/gas interface). The numerator is equal to the area between $\mu_{\mathrm{O}}^{\mathrm{I}}$ and $\mu_{\mathrm{O}}$ (a certain position, $x$, in the scale). The ratio of the two areas gives the relation between the position and the chemical potential of oxygen in the scale.

The chemical potential distribution of oxygen in the scale is shown in Fig. 9 as a function of a normalized position. The chemical potential at the metal/oxide interface is fixed at the equilibrium oxygen partial pressure of $\mathrm{Ni} / \mathrm{NiO}$. And the chemical potential at the oxide/gas interface is determined by that in the atmosphere. The chemical potential of oxygen decreases non-linearly from the oxide/gas interface (II) to the metal/oxide interface (I). The gradient of the chemical potential of oxygen increases as position closer to the metal/ oxide interface.

Since the chemical potential of oxygen in the scale could be expressed as a function of the position in the scale, the 


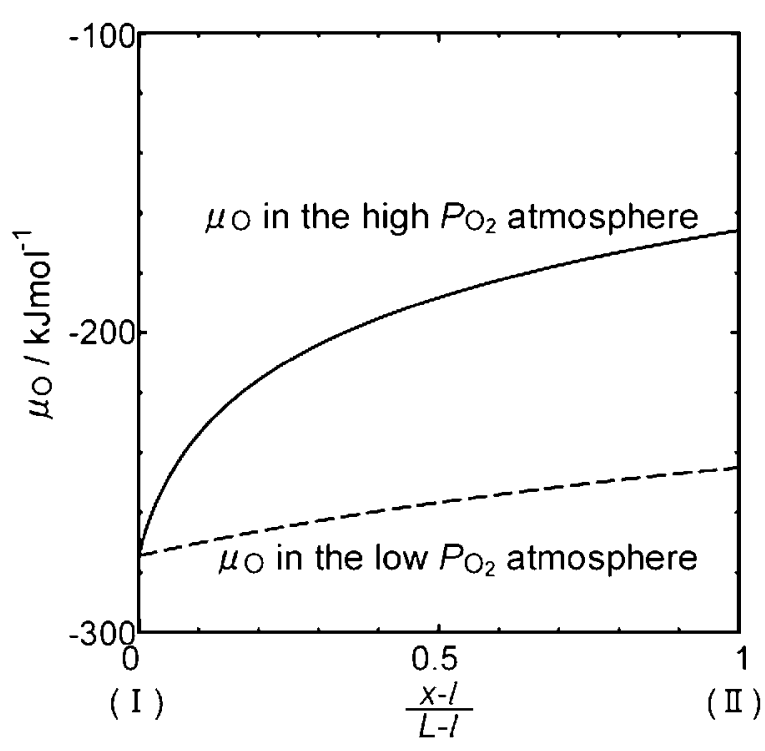

Fig. 9 Chemical potential distribution of oxygen in $\mathrm{NiO}$ scale versus normalized position in the scale. absolute mobility of the constituent ions, $B_{\mathrm{Ni}}$ and $B_{\mathrm{O}}$, the gradient of the electrochemical potential of oxygen, $d \eta_{\mathrm{O}} / d x$ given by the eq. (23), and $\alpha$ given by the eq. (14) can be also expressed as functions of the position in the scale.

\subsection{The flux of oxygen ion, its divergence of oxygen flux and formation/annihilation rate of oxide in $\mathrm{NiO}$ scale}

The formation/annihilation rate of oxide in the $\mathrm{NiO}$ scale, $\partial n_{\mathrm{NiO}} / \partial t$ can be expressed as a negative value of the divergence of the oxygen flux. Using the eq. (25), the oxygen flux in $\mathrm{NiO}$ scale is given as

$$
J_{\mathrm{O}}=-c_{\mathrm{O}} B_{\mathrm{O}}\left(d \eta_{\mathrm{O}} / d x\right)=-c_{\mathrm{O}} B_{\mathrm{O}} k /\{(L-l) \alpha\}
$$

The formation/annihilation rate of oxide in the $\mathrm{NiO}$ scale, $d n_{\mathrm{NiO}} / d t$ is written as

$$
\partial n_{\mathrm{NiO}} / \partial t=-\partial J_{\mathrm{O}} / \partial x=-\partial\left[-c_{\mathrm{O}} B_{\mathrm{O}} k /\{(L-l) \alpha\}\right] / \partial x
$$

In the case that $c_{\mathrm{O}}$ is constant, the eq. (49) can be written as

$172.8 \mathrm{ks}$

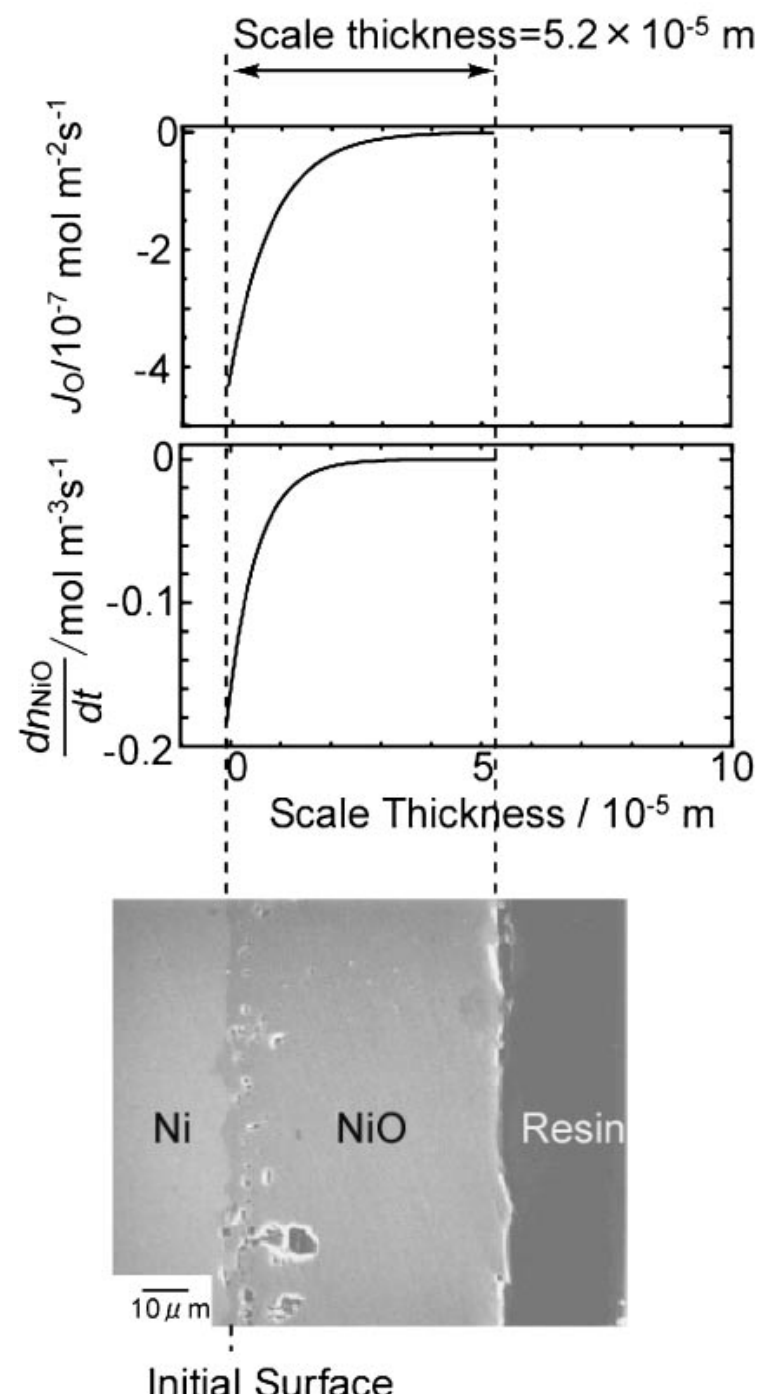

Initial Surface

Fig. 10 Comparison of cross-section images with the oxygen flux and the formation/annihilation rate of oxide in $\mathrm{NiO}$ scale in the high $P_{\mathrm{O}_{2}}$ atmosphere $\left(P_{\mathrm{O}_{2}}=2.1 \times 10^{4} \mathrm{~Pa}\right)$. 
$86.4 \mathrm{ks}$

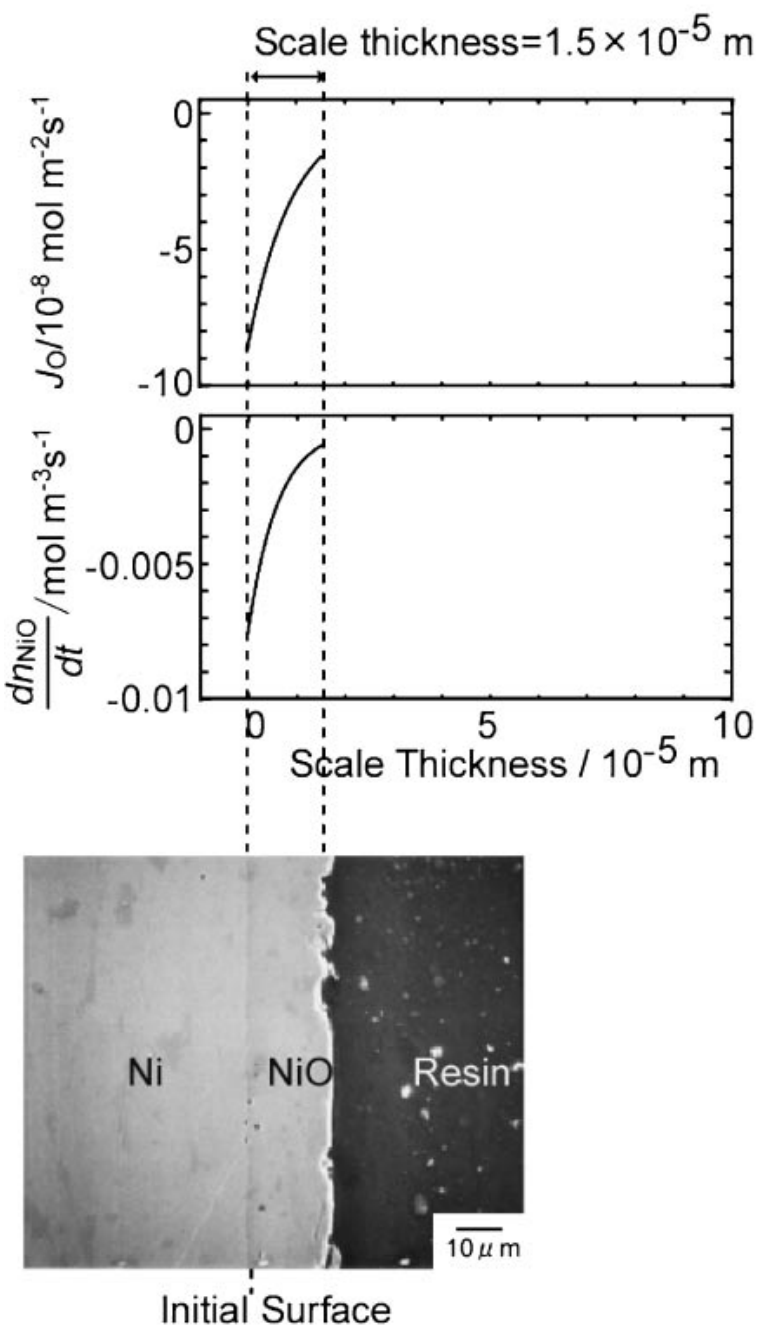

$172.8 \mathrm{ks}$

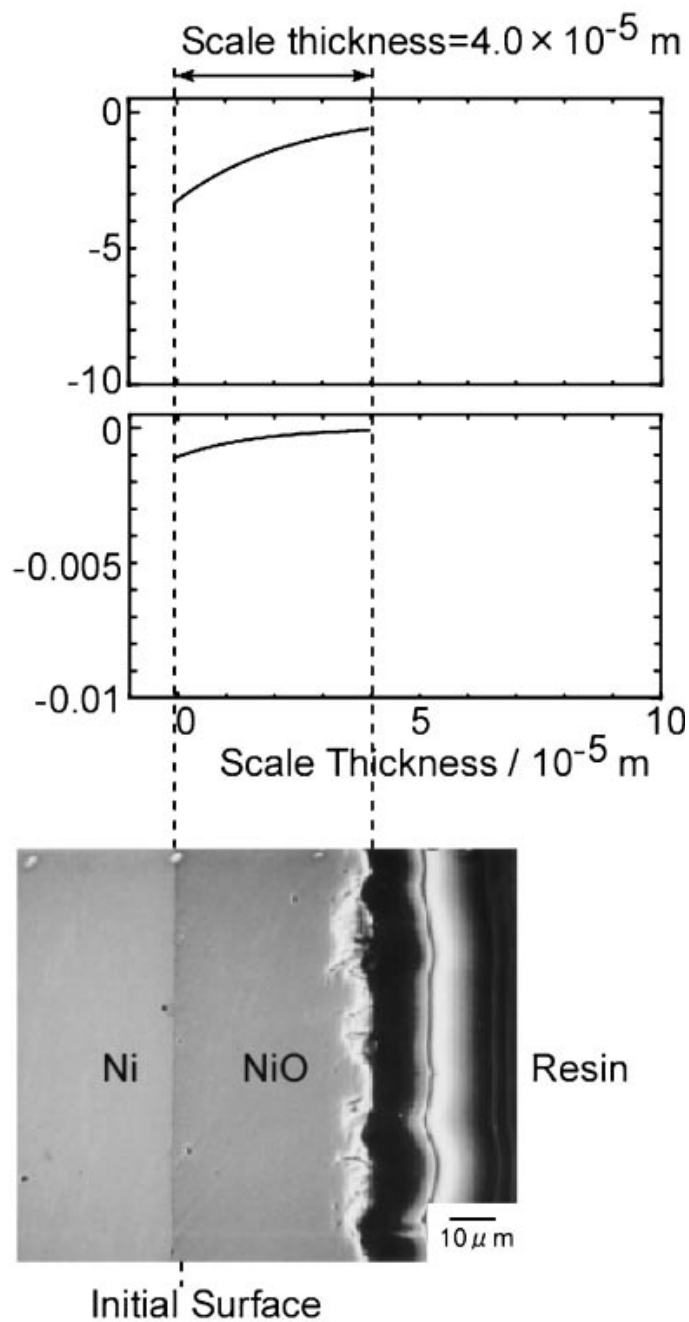

Fig. 11 Comparison of cross-section images with the oxygen flux and the formation/annihilation rate of oxide in $\mathrm{NiO}$ scale in the low $P_{\mathrm{O}_{2}}$ atmosphere $\left(P_{\mathrm{O}_{2}}=2.0 \times 10^{-2} \mathrm{~Pa}\right)$.

$$
\begin{aligned}
\partial n_{\mathrm{NiO}} / \partial t= & \left\{c_{\mathrm{O}} k /(L-l)\right\}\left\{\partial\left(B_{\mathrm{O}} / \alpha\right) / \partial x\right\} \\
= & \left\{c_{\mathrm{O}} k /(L-l)\right\}\left\{\partial\left(B_{\mathrm{O}} / \alpha\right) / \partial \mu_{\mathrm{O}}\right\}\left(\partial \mu_{\mathrm{O}} / \partial x\right) \\
= & {\left[c_{\mathrm{O}} k^{2} /\left\{(L-l)^{2} \alpha\right\}\right]\left\{\partial\left(B_{\mathrm{O}} / \alpha\right) / \partial \mu_{\mathrm{O}}\right\} } \\
= & {\left[c_{\mathrm{O}} k^{2} /\left\{(L-l)^{2} \alpha\right\}\right]\left[\left\{\alpha\left(\partial B_{\mathrm{O}} / \partial \mu_{\mathrm{O}}\right)\right.\right.} \\
& \left.\left.-B_{\mathrm{O}}\left(\partial \alpha / \partial \mu_{\mathrm{O}}\right)\right\} / \alpha^{2}\right] \\
= & {\left[z_{\mathrm{Ni}}^{2} c_{\mathrm{Ni}} c_{\mathrm{O}} k^{2} /\left\{(L-l)^{2} \alpha^{3}\right\}\right]\left\{B_{\mathrm{Ni}}\left(\partial B_{\mathrm{O}} / \partial \mu_{\mathrm{O}}\right)\right.} \\
& \left.-B_{\mathrm{O}}\left(\partial B_{\mathrm{Ni}} / \partial \mu_{\mathrm{O}}\right)\right\}
\end{aligned}
$$

As mentioned above, $B_{i}$ and $\alpha$ can represented as functions of the position in the scale, $J_{\mathrm{O}}$ and $\partial n_{\mathrm{NiO}} / \partial t$ can be also obtained against the position in the scale. If $\partial n_{\mathrm{NiO}} / \partial t$ is negative, the annihilation of oxide occurs at the position, resulting in the formation of voids.

Figure 10 shows the calculated oxygen flux, the formation/annihilation rate of oxide in the $\mathrm{NiO}$ scale and the microstructure of the scales formed in the high $P_{\mathrm{O}_{2}}$ atmosphere at two different oxidation times. The value of oxygen flux is negative since oxide ions flow from the scale/gas interface; i.e. negative direction. The oxygen flux is maximum at the metal/oxide interface.
The formation/annihilation rates exhibit negative values throughout scales. The void formation is expected in the $\mathrm{NiO}$ scale. The annihilation rate increases drastically in the vicinity of the metal/oxide interface. It indicates that voids mainly forms in the vicinity of the metal/oxide interface. And the rate of the voids formation is largest at the metal/ oxide interface. The observed cross-section indicates that the calculation can predict the void formation in the growing $\mathrm{NiO}$ scale.

Figure 11 shows the oxygen flux and the calculation of formation/annihilation rate of oxide in the $\mathrm{NiO}$ scale and the microstructure of the scales formed in the low $P_{\mathrm{O}_{2}}$ atmosphere at two different oxidation times. Although the tendencies of the flux and the annihilation rate are the same to that in the high $P_{\mathrm{O}_{2}}$ atmosphere, the calculation expects that its absolute value is smaller and cross-section shows the void formation is less than that in the high $P_{\mathrm{O}_{2}}$.

It is noteworthy that the annihilation rate of oxide decreases with time because the chemical potential gradient of ions decreases with increasing the scale thickness. 


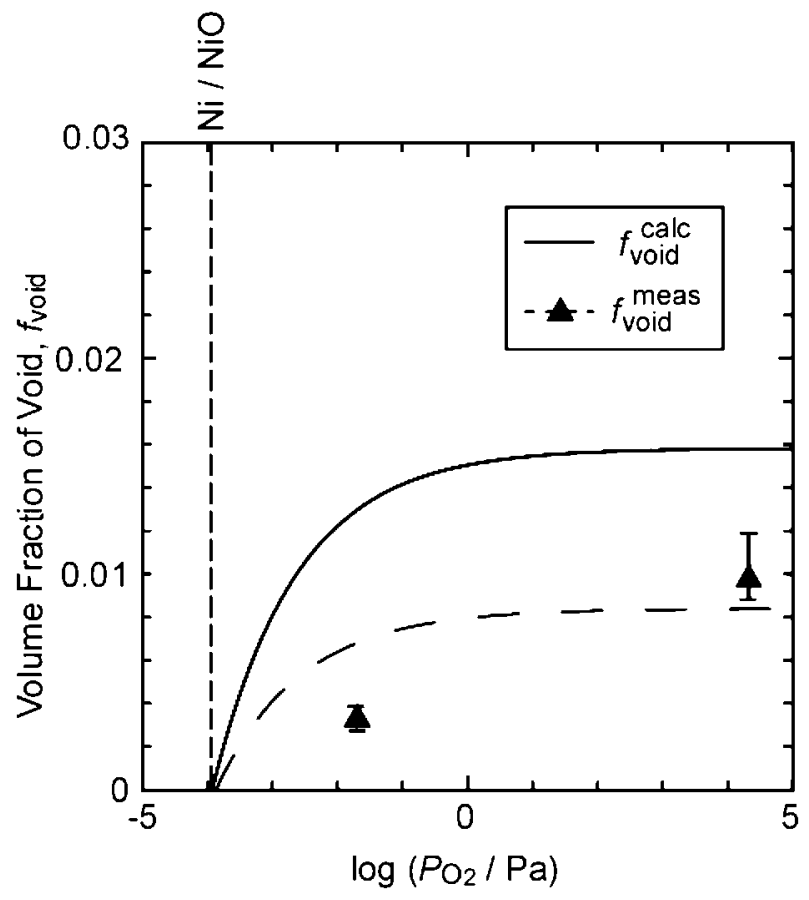

Fig. 12 The calculated volume fraction of voids in $\mathrm{NiO}$ scale and the area fraction of voids in the $\mathrm{NiO}$ scale measured on the cross-section images.

\subsection{Volume fraction of voids in $\mathrm{NiO}$ scale}

As seen in Fig. 4, the measured volume fraction of voids is independent of time as expected from eq. (39). The volume fraction of voids, $f_{\text {void }}^{\text {calc }}$ calculated using the eq. (39) with the eqs. (45) and (46) as a function of $P_{\mathrm{O}_{2}}$ and shown in Fig. 12. The fraction observed is a little smaller than that calculated. Extremely tiny voids may nucleate at many positions and the SEM observation in this study probably misses to count the tiny voids. But this calculation explained well the void formation and the morphology of scale.

\section{Conclusions}

From the calculation of the mass transport of ions in $\mathrm{NiO}$ scale formed at $1373 \mathrm{~K}$, void formation in the scale could be estimated. Voids always form in the vicinity of the metal/ oxide interface, and the formation rate of the void is the largest at the metal/oxide interface. The microstructure observation verified that this estimation can elucidate the voids formation in $\mathrm{NiO}$ scale quantitatively.

\section{Acknowledgements}

This research was financially supported in part by the Grant-in-Aid for Scientific Research on Priority Area, "Nanoionics (439) by the Ministry of Education, Culture, Sports, and Technology".

\section{REFERENCES}

1) T. Maruyama, N. Fukagai, M. Ueda and K. Kawamura: Mater. Sci. Forum 461-464 (2004) 807-814.

2) M. Ueda, K. Kawamura and T. Maruyama: Mater. Sci. Forum 522-523 (2006) 37-44.

3) M. Backhaus-Ricoult and R. Dieckmann: Ber. Bunsenges. Phys. Chem. 90 (1986) 690-698.

4) F. Millot, J. C. Lorin, B. Klossa, Y. Niu and J. R. Tarento: Ber. Bunsenges. Phys. Chem. 101 (1997) 1351-1354.

5) N. L. Peterson: Solid State Ionics 12 (1982) 201-215.

6) R. Haugsrud and T. Norby: Solid State Ionics 111 (1998) 323-332.

7) K. Fueki and J. B. Wagner Jr: J. Electrochem. Soc. 112 (1965) 384 388.

8) A. Atkinson and R. I. Taylor: Philos. Mag. A 39 (1979) 581-595.

9) A. Atkinson and R. I. Taylor: Philos. Mag. A 43 (1981) 979-998.

10) R. Haugsrud: Corros. Sci. 45 (2003) 211-235.

11) T. Maruyama, Y. Saito, T. Mochizuka and T. Amano: J. Electrochem. Soc. 134 (1987) 2915-2923.

12) R. Peraldi, D. Monceau and B. Pieraggi: Oxid. Met. 58 (2002) 249273.

13) R. Peraldi, D. Monceau and B. Pieraggi: Oxid. Met. 58 (2002) 275295.

14) F. A. Elrefaie, A. Manolescu and W. W. Smeltzer: J. Electrochem. Soc. 132 (1985) 2489-2493.

15) J. S. Sheasby and D. S. Cox: Oxid. Met. 37 (1991) 373-387.

16) W. D. Kingery, H. K. Bowen and D. R. Uhlmann: Introduction to Ceramics, Second Edition, (A Wiley-Interscience Publication, 1976) pp. 526-530.

17) V. S. Stubican and L. R. Carinci: Z. Phys. Chem. (Munich) 207 (1998) 215-222.

18) C. Dubois, C. Monty and J. Philibert: Solid State Ionics 12 (1984) 7578. 